\title{
Examining the relationship between adherence and satisfaction with antidepressant treatment
}

\author{
This article was published in the following Dove Press journal: \\ Neuropsychiatric Disease and Treatment \\ 4 August 2014 \\ Number of times this article has been viewed
}

\section{Khalaf Aljumah' \\ Azmi Ahmad Hassali² \\ Saed AIQhatani'}

'Al Amal Psychiatric Hospital, Department of Pharmacy, Riyadh, Saudi Arabia; ${ }^{2}$ Universiti Sains Malaysia, School of Pharmaceutical Sciences, Penang, Malaysia
Correspondence: Khalaf Aljumah Al Amal Psychiatric Hospital, Department of Pharmacy, PO Box 33626, Riyadh I I458, Saudi Arabia

Email khalafaljumaah@yahoo.com
Background: Adherence to antidepressant treatment is an essential step in the management of patients with major depressive disorder, and several factors can contribute to antidepressant nonadherence. Evidence supports the hypothesis that patient treatment satisfaction will result in improved adherence; therefore, the aim of this study was to investigate the relationship between patient treatment satisfaction and adherence to antidepressants, and the role of patient beliefs toward medication in patient treatment satisfaction.

Methods: This was an observational, nonexperimental survey of all patients attending Al Amal Psychiatric Hospital (500 beds) in Riyadh, Saudi Arabia. Medication adherence was assessed using the eight-item Morisky Medication Adherence Scale (MMAS-8), and treatment satisfaction was assessed using the Treatment Satisfaction Questionnaire for Medication (TSQM 1.4).

Results: A total of 403 patients met the inclusion criteria; $50.4 \%$ were females; participant age ranged from 18 to 60 years; and $16 \%$ of the patients reported side effects after using antidepressants. Both males and females reported high treatment satisfaction rates: $-79.21 \%$ (standard deviation [SD] 8.52) and 86.55\% (SD 14.34), respectively - with statistically significant associations found for female sex, older age, and three or more physician visits per year. Adherence to antidepressants was associated with treatment satisfaction with the antidepressants, with a direct positive correlation.

Conclusion: The results of this study showed high treatment satisfaction scores among patients in Saudi Arabia with major depressive disorder, which correlated with adherence and patient beliefs about the necessity of treatment. This finding has improved the understanding of the role of patient beliefs, which can help caregivers and other stakeholders to improve satisfaction with antidepressants.

Keywords: patient beliefs, morisky scale, treatment satisfaction questionnaire, antidepressant

\section{Introduction}

Adherence to antidepressant treatment is an essential step for the management of patients with major depressive disorder, ${ }^{1}$ which can change from early to late treatment stages - it has been shown that $28 \%$ of patients discontinue medication after 1 month and that between $44 \%$ and $52 \%$ of patients discontinue medication after 3 months. ${ }^{2}$ Recent data from Saudi Arabia has reported that $52.9 \%$ of patients have low adherence to antidepressant medication. ${ }^{3}$

Low adherence to antidepressants can lead to serious complications, for example, disease recurrence, relapse, increase in the cost of treatment, and impairment in daily functioning. ${ }^{1,2}$ Several factors that influence low adherence to antidepressant treatment include environmental factors, such as poverty, homelessness, and other socioeconomic conditions. Other factors, such as persistence of symptoms, side effects, complexity of the prescription, and satisfaction with treatment, have been reported to have associations with low adherence. ${ }^{3-6}$ 
Treatment satisfaction can be defined as "the sum of the patient perceptions and expectations about the treatment". ${ }^{7-9}$ If the perceived expectations are met, the patient will be satisfied. Otherwise, patients have reported a low satisfaction level when there was a clear discrepancy between their high expectations and their low evaluation of treatment received.${ }^{10}$ Additionally, satisfaction can be defined as "the health care recipient's reaction to salient aspects of his or her treatment experience". ${ }^{9}$ However, treatment satisfaction can be influenced by the effectiveness of treatment, the side effects, and the convenience of the dosage format and frequency of treatment, which, at the same time, influence adherence to medication. ${ }^{11}$

Assuming that different experiences among patients will result from use of different pharmacological classes of antidepressants, rationally, this experience will affect patient satisfaction with antidepressants. ${ }^{11}$ Further, patient satisfaction with antidepressants is believed to be affected by positive initial beliefs toward those antidepressants. ${ }^{12,13}$

Patients with chronic disease report lower treatment satisfaction, with low adherence to treatment. ${ }^{14,15}$ One recent review reported evidence on the association between treatment satisfaction and the level of adherence to treatment, but few studies in this review used a statistical method to test the association between treatment satisfaction and the level of adherence. ${ }^{16}$ The available data suggested a positive relationship between treatment satisfaction and the level of adherence. ${ }^{16}$

It has become increasingly important to assess treatment satisfaction as it relates to adherence; however, it is unclear what factors influence treatment satisfaction. A review of the literature revealed that many issues related to patient satisfaction with antidepressants remain unexplored, with no studies on satisfaction with antidepressant treatment among patients from Saudi Arabia. Therefore, the aim of this study was to investigate the relationship between patient treatment satisfaction and adherence to antidepressants, and the role of patient beliefs about antidepressants in patient treatment satisfaction. Additionally, this study evaluated the statistical association between these concepts.

\section{Methods}

A nonexperimental, observational design was used to evaluate adherence to medications as well as treatment satisfaction, among patients with major depressive disorder. Patients were recruited from the outpatient clinic at the $\mathrm{Al}$ Amal Hospital (psychiatric hospital) in Riyadh, between August 2013 and January 2014. The Al Amal hospital has 500 beds and provides psychiatric care to the population of the entire capital city of Saudi Arabia.

\section{Study population}

The inclusion criteria were: patients diagnosed with major depressive disorder according to the Diagnostic and Statistical Manual of Mental Disorders, Fourth Edition (DSM-IV); ${ }^{17}$ age range from 18 to 60 years; history of major depressive disorder for at least 6 months; and using at least one antidepressant medication. Patients having a psychosis, history of bipolar disorder or history of drug dependency, and patients using concomitant medications other than antidepressant were excluded from study. All patients who met the inclusion criteria were invited to participate after a briefing about the aims and specific objectives of this study. Written consent was obtained from all patients.

\section{Ethical consideration}

Ethical approval was sought from the local training and research committee at Al Amal Hospital in Riyadh, Saudi Arabia.

\section{Data collection}

Data were collected from the eligible participants by the research coordinator. Validated scales were used, including the Medication Adherence Questionnaire (MMAQ), Treatment Satisfaction Questionnaire for Medication (TSQM 1.4), and Beliefs about Medicine Questionnaire (BMQ-Specific and General), while other demographic data and study variables were collected during the interview.

Patient adherence was assessed indirectly using the Arabic version of the MMAQ, ${ }^{18}$ a well-validated instrument developed by Morisky et al. ${ }^{19-22}$ The MMAQ has good validity and has been proven to be a useful screening technique for adherence to antidepressant medication ${ }^{23}$ and for Arabic patients. ${ }^{12,18,24}$ It consists of eight items that are formulated in a way to avoid acquiescence bias; the total score of the MMAQ ranges from $0-8$, with higher scores representing higher adherence.

Treatment satisfaction was measured by the Arabic version of the self-reporting TSQM 1.4, which has psychometrically robust and proven validity and reliability with Arabic patients. ${ }^{2,24}$ The TSQM 1.4 features a 14-item scale consisting of four dimensions, ${ }^{11}$ including effectiveness, side effects, convenience dimension, and global satisfaction (patients were instructed not to respond to the questions in the side effects dimension if they were not suffering from side effects). The TSQM 1.4 domain scores ranged from 0-100, 
with higher scores representing higher satisfaction in that domain. ${ }^{25,26}$

The patients' beliefs were assessed using the Arabic version of the BMQ-Specific and General, a self-reporting measure of proven validity and reliability in general medical Arabic patients ${ }^{18}$ and in patients with major depressive disorder. ${ }^{2,27}$ The BMQ-Specific contains two parts: the Necessity subscale measures patients' beliefs about the necessity and importance of their medication; and the Concern subscale measures patients' beliefs about general worries, dependency, mystery, and disruption toward life (long-term effects). Each of two parts has a score ranging from 5-25.,27 The BMQGeneral also contains two parts: the Harm subscale measures beliefs that medicines in general are harmful, addictive, and poisonous; and the Overuse subscale measures beliefs that medicines in general are overused by doctors.

\section{Statistical methods and sample size}

The sample size calculation was based on $52 \%$ as the average proportion of patient nonadherence to antidepressants, and a confidence level of $95 \% .{ }^{28}$ A total of 403 patients were recruited to conduct the study. Descriptive and comparative statistics were analyzed with the Statistical Package for Social Sciences (SPSS Statistics for Windows, Version 17; SPSS Inc., Chicago, IL, USA). Analysis of covariance (ANCOVA) analyses were conducted to assess the differences in the treatment satisfaction, medication adherence, and beliefs between groups. An independent sample $t$-test was conducted to compare the overall mean treatment satisfaction between the groups. To investigate the relationship and correlation between treatment satisfaction and adherence, Pearson correlation coefficients and mutable regression (stepwise method) were used.

\section{Results}

A total of 403 patients met the inclusion criteria and participated in this study, with the patient characteristics being shown in Table 1. A total 203 participants, representing $50.4 \%$ of the total study sample, were females, whereas the remaining 200 (49.6\%) were males. The participant ages ranged from 18 to 60 years, with an average of 39 years

Table I Characteristics of study participants and their level of treatment satisfaction

\begin{tabular}{|c|c|c|c|}
\hline Factor & $\mathbf{N}(\%)$ & $\begin{array}{l}\text { Treatment } \\
\text { satisfaction (mean) }\end{array}$ & SD \\
\hline \multicolumn{4}{|l|}{ Sex } \\
\hline Male & $200(49.6)$ & 79.21 & 8.52 \\
\hline Female** & $203(50.4)$ & 86.55 & 14.34 \\
\hline \multicolumn{4}{|l|}{ Age } \\
\hline $18-30$ years & $102(25.1)$ & 78.98 & 11.93 \\
\hline $31-40$ years & $120(29.9)$ & 82.65 & 13.10 \\
\hline $4 I-50$ years & $102(25.1)$ & 85.08 & 13.84 \\
\hline $5 \mathrm{I}-60$ years $*$ & $80(19.8)$ & 86.68 & 8.93 \\
\hline \multicolumn{4}{|l|}{ Education level } \\
\hline No formal education & $90(22.5)$ & 84.92 & 13.98 \\
\hline Primary & $58(14.4)$ & 82.61 & 8.42 \\
\hline Intermediate & $80(19.8)$ & 82.41 & 13.42 \\
\hline Secondary & $130(32.1)$ & 83.58 & 11.82 \\
\hline College/bachelor degree & $45(11.2)$ & 80.24 & 14.48 \\
\hline \multicolumn{4}{|c|}{ Number of antidepressant drugs currently taken } \\
\hline One & $331(82.3)$ & 83.20 & 12.64 \\
\hline Two & $72(17.7)$ & 82.84 & 12.08 \\
\hline \multicolumn{4}{|l|}{ Number of clinic visit per year } \\
\hline Once a year & $28(7.0)$ & 67.53 & 8.47 \\
\hline Twice a year & $4 \mid(10.2)$ & 78.55 & 9.41 \\
\hline Three times a year* & 149 (36.9) & 88.46 & 13.66 \\
\hline Four times a year* & $185(46.0)$ & 82.23 & 9.94 \\
\hline \multicolumn{4}{|l|}{ Illness duration } \\
\hline$\leq 3$ years & II $4(28.3)$ & 81.38 & 12.01 \\
\hline$>3$ years to 6 years & $92(23.0)$ & 82.63 & $|4.3|$ \\
\hline$>6$ years to 9 years & $172(42.8)$ & 83.96 & 12.17 \\
\hline$>9$ years & $23(5.9)$ & 87.57 & 9.44 \\
\hline
\end{tabular}

Notes: Student's $t$-test for the difference in the characteristics of the study according to the level of treatment satisfaction. *Mean difference is significant at $P<0.05$. **Mean difference is significant at $P<0.01$.

Abbreviation: SD, standard deviation. 
Table 2 Types of antidepressants and combination used in this study

\begin{tabular}{lll}
\hline Type of antidepressant drugs & Frequency & $\%$ \\
\hline TCA & 45 & 11.2 \\
SSRI & $2 I I$ & 52.4 \\
SNRI & 34 & 8.6 \\
Other & 47 & 11.8 \\
TCA + SSRI & 19 & 4.8 \\
TCA + SNRI & 5 & 1.6 \\
SSRI + SNRI & 21 & 5.3 \\
SNRI + other & 4 & 1.1 \\
SSRI + SNRI + other & 17 & 3.2 \\
Total & 403 & 100.0 \\
\hline Ab
\end{tabular}

Abbreviations: SNRI, serotonin-norepinephrine reuptake inhibitor; SSRI, selective serotonin reuptake inhibitor; TCA, tricyclic antidepressant.

(standard deviation [SD] 11), and 89\% of the participants had a high school education level or lower. The majority of the participants $(82.4 \%)$ currently used one antidepressant medication.

Only $16 \%$ of the patients reported side effects after using antidepressants, and only $6.7 \%$ were using more than one antidepressant. Half of the patients were on selective serotonin reuptake inhibitor (SSRI) types of antidepressants, and the combination used by patients in this study are shown in detail in Table 2; however, there were small differences in patients' reported adherence scores between the groups, with no significant difference; the same was true between patients who reported side effects (4.83 [SD 1.82]) or not (5.27 [SD 1.98]), with no significant difference.

Both the males and females reported high treatment satisfaction rates (79.21\% [SD 8.52] and 86.55\% [SD 14.34], respectively), with statistically significant associations found for female sex, older age, and three or more physician visits per year. However, education level, duration of treatment, number of medications per prescription, and the pharmacological group of the antidepressant medication were not statistically associated with treatment satisfaction with the antidepressant medication.
Adherence to antidepressants was associated with treatment satisfaction with antidepressants, as shown in Table 3. A significant difference was seen between the low- and high-adherence groups in reporting treatment satisfaction (80.83\% [SD 14.27], 85.72\% [SD 9.62]); moreover, the score of effectiveness and global satisfaction showed significant differences between the low and high adherence groups; however the side effects and convenience domains did not show differences (Table 3).

A direct positive correlation between adherence to antidepressants and treatment satisfaction was shown by the Pearson correlation coefficient test (0.1104); however, no association was found between the level of adherence and the four components of the TSQM scales (Table 4).

Specific patient necessity and concern beliefs about antidepressants showed a direct association with patient treatment satisfaction, on all domains of the TSQM scales except side effects. However, the general patient overuse and harm beliefs showed a direct positive correlation with the side effects domain, and global satisfaction showed a direct correlation with patient beliefs (Table 4).

\section{Discussion}

The aim of this study was to examine the association of treatment satisfaction and adherence to antidepressants, and the role of beliefs about medication, in patients with major depressive disorder. To the best of our knowledge, this study is the first to examine the relationship between treatment satisfaction and adherence, and the role of patient beliefs among patients with major depressive disorder in Saudi Arabia.

Studies on treatment satisfaction with antidepressants provide important data about patient satisfaction with their medications and its impact on medication-taking behavior, as well as helping stakeholders to understand the patients' experience with different types of antidepressants. This, in

Table 3 Patient satisfaction with antidepressant and level of adherence

\begin{tabular}{|c|c|c|c|c|c|c|}
\hline \multirow[t]{2}{*}{ Factor } & \multicolumn{2}{|c|}{ Low adherence $(\mathbf{N}=99)$} & \multicolumn{2}{|c|}{ High adherence $(\mathbf{N}=\mathbf{8 8})$} & \multirow[t]{2}{*}{$t$-value } & \multirow[t]{2}{*}{$P$-value } \\
\hline & Mean & SD & Mean & SD & & \\
\hline TSQM & 80.83 & 14.27 & 85.72 & 9.62 & 2.775 & $0.006 * *$ \\
\hline Effectiveness & 78.38 & 16.95 & 83.39 & 14.26 & 2.169 & $0.03 I^{*}$ \\
\hline Side effects & 71.32 & 15.44 & 70.91 & 14.97 & 0.070 & 0.944 \\
\hline Convenience & 88.14 & 11.99 & 90.96 & 8.36 & 1.875 & 0.062 \\
\hline Global satisfaction & 77.90 & 16.85 & 83.42 & 12.97 & 2.527 & $0.012 * *$ \\
\hline
\end{tabular}

Notes: Student's $t$-test for the difference according to the level of adherence. *Mean difference is significant at $P<0.05$. $* *$ Mean difference is significant at $P<0.0$ I. Abbreviations: TSQM, Treatment Satisfaction Questionnaire for Medication; SD, standard deviation. 
Table 4 Pearson correlation coefficients between the factors of the TSQM and level of adherence and patient beliefs

\begin{tabular}{llllll}
\hline Factor & General overuse & General harm & Necessity beliefs & Concern beliefs & Level of adherence \\
\hline Effectiveness & -0.0338 & 0.0181 & $0.2913^{*}$ & $-0.2932^{* *}$ & 0.0776 \\
Side effects & $0.1053^{* *}$ & $0.1570^{* *}$ & -0.0264 & -0.0303 & -0.0948 \\
Convenience & 0.0130 & -0.0478 & $0.2276^{*}$ & $-0.206 I^{* *}$ & 0.0403 \\
Global satisfaction & $-0.1247^{* *}$ & $-0.1293^{* *}$ & $0.4103^{*}$ & $-0.3338^{* *}$ & 0.0938 \\
TSQM & -0.0586 & $-0.1184^{* *}$ & $0.3096^{*}$ & $-0.3046^{* *}$ & $0.1104^{*}$ \\
\hline
\end{tabular}

Notes: *Direct positive correlation. **Inverse negative correlation.

Abbreviation: TSQM, Treatment Satisfaction Questionnaire for Medication.

turn, helps with future planning for proper intervention to improve the clinical outcomes of depression.

The results of this study indicated high satisfaction scores: the average score was 83.27 among patients with major depressive disorder, even among patients reporting side effects after using antidepressants. This finding may be explained by the low education of the patients since $89 \%$ of the participants had a high school education or less, which is consistent with the literature showing that patient satisfaction is higher among patients with lower education. ${ }^{3,29}$ Additionally, treatment satisfaction was associated significantly with three or more follow-up psychiatric clinic visits per year, representing $82.9 \%$ of the participant sample, which is consistent with the findings from a review of the literature. ${ }^{13}$

The positive association between treatment satisfaction and adherence to antidepressants in this study is consistent with theoretical models in which satisfaction with treatment leads to positive medication-taking behaviors. It is also similar to the finding from 16 studies reported in a recent review of the literature. ${ }^{16}$ The results of this study provide further support to the theory that treatment satisfaction is positively associated with adherence.

In this study, the patient beliefs and adherence showed no correlation with report of side effects in patients with major depressive disorder - this may be explained by the fact that only $16 \%$ of the patients reported side effects compared with other studies, where this reached up to $23 \% .{ }^{30}$ Moreover, half those who reported side effects used SSRIs as the antidepressant agents, which have a favorable side effect profile compared with older tricyclic antidepressants, lower discontinuation rate, and better adherence. ${ }^{30}$

The direct positive correlation of the reporting of side effects during this study with patients general beliefs scores (for overuse and harm) was incompatible with the hypothesis that patients with negative beliefs about their medications report more side effects. ${ }^{31}$

This study has some important strengths, including a wide range of inclusion, use of well-validated scales, and assessment of specific patient beliefs about medication, but still had several limitations. First, the nonexperimental, crosssectional design of this study cannot determine causation. Second, an indirect tool to evaluate patient adherence was used. Third, use of self-reporting questionnaires in this study represents a potential limitation; however, it should be noted that such questionnaires are commonly used in this kind of research. Finally, this study did not investigate patient involvement in treatment decisions or the patient-physician relationship, at least to explain the positive correlation between treatment satisfaction with antidepressants and the number of psychiatric clinic visits per year.

A prospective study is needed to understand the real mechanisms through which treatment satisfaction is associated with adherence to antidepressants, and to understand ways to enhance treatment satisfaction with antidepressants, and the impact of enhanced treatment satisfaction on patients' clinical outcomes.

\section{Conclusion}

Among patients with major depressive disorder in Saudi Arabia, treatment satisfaction was found to be positively correlated with adherence and necessity beliefs. This finding has improved the understanding of treatment satisfaction with antidepressants and the role of patient beliefs. These results can help caregivers and stakeholders to improve adherence to antidepressants, by addressing treatment satisfaction using a systematic approach based on these findings. Further research is also recommended in order to investigate other factors that may influence treatment satisfaction.

\section{Disclosure}

The authors report no conflicts of interest in this work.

\section{References}

1. Sawada N, Uchida H, Suzuki T, et al. Persistence and compliance to antidepressant treatment in patients with depression: a chart review. BMC Psychiatry. 2009;9:38.

2. Hunot VM, Horne R, Leese MN, Churchill RC. A cohort study of adherence to antidepressants in primary care: the influence of antidepressant concerns and treatment preferences. Prim Care Companion J Clin Psychiatry. 2007;9(2):91-99. 
3. Al-Jumah KA, Qureshi NA. Impact of pharmacist interventions on patients' adherence to antidepressants and patient-reported outcomes: a systematic review. Patient Prefer Adherence. 2012;6:87-100.

4. Ellis JJ, Erickson SR, Stevenson JG, Bernstein SJ, Stiles RA, Fendrick AM. Suboptimal statin adherence and discontinuation in primary and secondary prevention populations. J Gen Intern Med. 2004; 19(6):638-645.

5. Osterberg L, Blaschke T. Adherence to medication. N Engl J Med. 2005; 353(5):487-497.

6. Ingersoll KS, Cohen J. The impact of medication regimen factors on adherence to chronic treatment: a review of literature. J Behav Med. 2008;31(3):213-224.

7. Ware JE, Snyder MK, Wright WR, Davies AR. Defining and measuring patient satisfaction with medical care. Eval Program Plann. 1983; $6(3-4): 247-263$.

8. Pascoe GC. Patient satisfaction in primary health care: a literature review and analysis. Eval Program Plann. 1983;6(3-4):185-210.

9. Cleary PD, McNeil BJ. Patient satisfaction as an indicator of quality care. Inquiry. 1988;25(1):25-36.

10. Ikegami N, Kawakita H. Patient satisfaction and hospital management policy. Jpn Hosp. 1987;6:11-15.

11. Bharmal M, Payne K, Atkinson MJ, Desrosiers MP, Morisky DE, Gemmen E. Validation of an abbreviated Treatment Satisfaction Questionnaire for Medication (TSQM-9) among patients on antihypertensive medications. Health Qual Life Outcomes. 2009;7:36.

12. Sweileh WM, Ihbesheh MS, Jarar IS, et al. Self-reported medication adherence and treatment satisfaction in patients with epilepsy. Epilepsy Behav. 2011;21(3):301-305.

13. Liekens S. Patients' Beliefs Towards Antidepressants [doctoral seminar]. Leuven: University of Leuven; 2012.

14. Biderman A, Noff E, Harris SB, Friedman N, Levy A. Treatment satisfaction of diabetic patients: what are the contributing factors? Fam Pract. 2009;26(2):102-108.

15. Zyoud SH, Al-Jabi SW, Sweileh WM, Morisky DE. Relationship of treatment satisfaction to medication adherence: findings from a crosssectional survey among hypertensive patients in Palestine. Health Qual Life Outcomes. 2013;11:191.

16. Barbosa CD, Balp MM, Kulich K, Germain N, Rofail D. A literature review to explore the link between treatment satisfaction and adherence, compliance, and persistence. Patient Prefer Adherence. 2012;6: 39-48.

17. American Psychiatric Association. Diagnostic And Statistical Manual Of Mental Disorders DSM-IV-TR. 4th ed. American Psychiatric Association: Arlington; 2000.
18. Alhalaiqa F, Deane KH, Nawafleh AH, Clark A, Gray R. Adherence therapy for medication non-compliant patients with hypertension: a randomised controlled trial. J Hum Hypertens. 2012;26(2):117-126.

19. Morisky DE, Ang A, Krousel-Wood M, Ward HJ. Predictive validity of a medication adherence measure in an outpatient setting. $J$ Clin Hypertens (Greenwich). 2008;10(5):348-354.

20. Morisky DE, Green LW, Levine DM. Concurrent and predictive validity of a self-reported measure of medication adherence. Med Care. 1986; 24(1):67-74.

21. Krousel-Wood M, Islam T, Webber LS, Re RN, Morisky DE, Muntner P. New medication adherence scale versus pharmacy fill rates in seniors with hypertension. Am J Manag Care. 2009;15(1):59-66.

22. Morisky DE, DiMatteo MR. Improving the measurement of self-reported medication nonadherence: response to authors. J Clin Epidemiol. 2011;64(3):255-257; discussion 258-263.

23. George CF, Peveler RC, Heiliger S, Thompson C. Compliance with tricyclic antidepressants: the value of four different methods of assessment. Br J Clin Pharmacol. 2000;50(2):166-171.

24. Sweileh WM, Ihbesheh MS, Jarar IS, et al. Antipsychotic medication adherence and satisfaction among Palestinian people with schizophrenia. Curr Clin Pharmacol. 2012;7(1):49-55.

25. Atkinson MJ, Sinha A, Hass SL, et al. Validation of a general measure of treatment satisfaction, the Treatment Satisfaction Questionnaire for Medication (TSQM), using a national panel study of chronic disease. Health Qual Life Outcomes. 2004;2:12.

26. Atkinson MJ, Kumar R, Cappelleri JC, Hass SL. Hierarchical construct validity of the treatment satisfaction questionnaire for medication (TSQM version II) among outpatient pharmacy consumers. Value Health. 2005;8 Supp1 1:S9-S24.

27. Brown C, Battista DR, Bruehlman R, Sereika SS, Thase ME, Dunbar-Jacob J. Beliefs about antidepressant medications in primary care patients: relationship to self-reported adherence. Med Care. 2005;43(12): 1203-1207.

28. Bulloch AG, Patten SB. Non-adherence with psychotropic medications in the general population. Soc Psychiatry Psychiatr Epidemiol. 2010; 45(1):47-56.

29. Kaldenberg DO. Patient satisfaction and health status. Health Mark $Q$. 2001;18(3-4):81-101.

30. Bosworth HB, Oddone EZ, Weinberger M, editors. Patient Treatment Adherence: Concepts, Interventions, and Measurement. New York, NY: Psychology Press; 2006.

31. Nestoriuc Y, Orav EJ, Liang MH, Horne R, Barsky AJ. Prediction of nonspecific side effects in rheumatoid arthritis patients by beliefs about medicines. Arthritis Care Res (Hoboken). 2010;62(6):791-799.
Neuropsychiatric Disease and Treatment

\section{Publish your work in this journal}

Neuropsychiatric Disease and Treatment is an international, peerreviewed journal of clinical therapeutics and pharmacology focusing on concise rapid reporting of clinical or pre-clinical studies on a range of neuropsychiatric and neurological disorders. This journal is indexed on PubMed Central, the 'PsycINFO' database and CAS,
Dovepress

and is the official journal of The International Neuropsychiatric Association (INA). The manuscript management system is completely online and includes a very quick and fair peer-review system, which is all easy to use. Visit http://www.dovepress.com/testimonials.php to read real quotes from published authors. 